\title{
Our Current NIH Funding Dilemma: Reform Our Process Or Remain In The Bog?
}

Robert A Orlando*

Department of Biochemistry and Molecular Biology, BMSB 249, MSC08 4670, 1 University of New Mexico, Albuquerque, NM 87131, USA

\section{Our Funding Crisis - The Losses We Have Sustained}

The customary NIH review process is experiencing increasing criticism with questions being raised regarding bias, competency, fairness, and reliability [1-3]. Concerns are expressed about mismatch in expertise between applicants and reviewers, anonymity of reviewers reducing accountability, and inconsistencies in scoring between reviewers. Such concerns are troubling indicators of a review process that has not evolved with the increased specialization and complexities of modern research $[4,5]$. Much needed debate continues as to whether reform is needed by way of restructuring or complete overhaul; yet, plausible recommendations on how to accomplish this are sorely lacking. Understandably, frustrations run high in the current funding climate with dropping pay lines, increased competition for limited, often declining funds, and questionable reviews from the Study Sections we once revered for their level of expertise, their constructive approach to reviewing, and their unyielding intellectual support and mentorship for scientific advancement.

Much is at stake for the future of U.S. biomedical research. U.S. funding has historically provided the major contributions to global improvement in the health and longevity of individuals and populations in developed countries [6]. With the remarkable advances made in basic discoveries over the past several decades, sustained, long-term investments are necessary to continue translating these discoveries into clinically useful treatments; as well as preventing stagnation of our national research capability. In spite of this need, the U.S. is rapidly losing ground as the preeminent research nation. The U.S. has the slowest annual growth rate in research dollars (1.5\%/year), followed by Europe (4.1\%/year), and Canada (4.5\%/year) [6]. Most notably, the Asian countries increased research funding from $\$ 28$ billion in 2004 to $\$ 52.4$ billion in 2011 (9.4\%/year), with the largest increases in China, India, South Korea, and Singapore [6]. Based on this financial reality, our chant becomes, "Congress needs to increase appropriations for research funding in order for us to keep pace with other developed nations". Thus far, our chant is heard, but to no effect. Competing priorities are a sobering reality for U.S. budget management and decision making. U.S. citizens face continued economic challenges with a seemingly endless war on global terrorism [7], providing health care for the many who lack coverage [8], and a continually rising national debt to meet some of the most basic obligations. In this light, the option of revitalizing the NIH budget to levels that are capable of funding upwards of $20-30 \%$ of applications is not a likely scenario in the near future, or even within the career time of mid-career investigators [9].

Continued stagnation in research funding will only accelerate the decline in global competitiveness among U.S. scientists [10]. Perhaps worse is the interruption of the processive nature of scientific discoveries. The continuity of scientific discovery relies heavily upon the processive accumulation of knowledge that serves to inform future investigations and the training of future scientists. Our research productivity as a scientific community is measured by our collective knowledge. Few of us can claim to have identified a "cure" for a medical malady, yet this does not diminish our individual contributions to the future of U.S. science. Through a life of dedication, sacrifice, and persistence, we each add our knowledge to the whole with the hope and anticipation that our discoveries will catapult other scientists to make their contributions, or perhaps find the elusive "cure". In addition, we are also experiencing losses among our ranks of established scientists. We are no longer in a time or place to make predictions that our current funding crisis will result in the loss of well-trained, seasoned investigators in their prime; the loss of active U.S. scientists is happening now and jeopardizing our ability to maintain the continuity of scientific discovery [11,12]. Many of us have personally witnessed our colleagues suffer in solitude because of non-renewed funding, the inability to continue their contributions to advance science, lost opportunities to train the next generation of scientists, and ultimately the anguish of closing their lab door and ending their research careers. Many of our colleagues are not the new, untested scientists who are unable to meet the challenges of peer-review and manage the rigors of advancement in the academic and private sector. Our colleagues are those who have met all of these challenges and succeeded; they are the Associate and Full Professors in Academia and Senior Scientists in Industrial Research and Development, all at a critical point in their careers when they can contribute the most to the scientific community with their seasoned experience. Recovering from this loss will likely take decades due to the lengthy training period needed to fully develop a competent and seasoned investigator. And only then will we have restored our research capacity to pick up where our generation has left off and try to make up so much lost ground in basic research. As NIH Director Francis Collins recently stated in an interview on C-SPAN, "Research isn't like a spigot that you turn on and off at will. If we lose scientists, they're not coming back when things get better." [12]

Many of the current funding opportunities available from NIH are supporting the concept of translational research in order to move basic discoveries into clinical application faster and more efficiently. Certainly this rationale has merit and is supported by the majority of the research community; but, questions are being raised asking if this funding realignment is at a disproportionate cost to basic research which provides the fundamental knowledge that most biomedical applications are built upon [13]. Surely this will be debated into our futures and only with time will answers be found to address this. However, it is apparent that funding for basic research is waning, while funding for translational research is remaining steady or even

*Corresponding author: Robert A Orlando, Department of Biochemistry and Molecular Biology, BMSB 249, MSC08 4670, 1 University of New Mexico, Albuquerque, NM 87131, USA, Tel: 505-272-5593; Fax: 505-272-5593; E-mail: rorlando@salud.unm.edu

Received Octomber 27, 2014; Accepted July 20, 2015; Published July 27, 2015

Citation: Orlando RA (2015) Our Current NIH Funding Dilemma: Reform Our Process Or Remain In The Bog? J Biomol Res Ther 4: 129. doi:10.4172/2167-7956.1000129

Copyright: ( 2015 Orlando RA. This is an open-access article distributed under the terms of the Creative Commons Attribution License, which permits unrestricted use, distribution, and reproduction in any medium, provided the original author and source are credited. 
advancing, albeit slowly [14]. Is this sustainable into the future? Not likely as the past has shown us. Without advancement of fundamental biological and medical knowledge, progress in clinical research can be hampered being limited by descriptive outcomes [15]. These limitations are best overcome with accompanying evidence addressing mechanisms-of-action that provides foundational knowledge for a systematic understanding of medical treatment, refinement of therapeutic approaches, and caution for potential harmful side-effects.

\section{An Opportunity for Renewal}

Facing little change in the future funding portfolio from NIH, what can we do to weather the storm to continue our growth of basic science knowledge and rescue early- and mid-career scientists so as to prevent an irreversible brain drain? Perhaps, as a scientific community we need to address the structure of NIH from its Institutes, Divisions, and down to the structure, composition, and focus of the individual Study Sections. The NIH research structure was established decades ago when the Division of Research Grants first opened its doors in 1946. By 1960 there were ten institutes increasing to 15 by 1970 . By 1998 the NIH had 27 institutes and centers. The number of standing and special emphasis Study Sections has grown at a remarkable rate to keep pace with many new, complex research agendas. As time and research productivity has shown, the NIH structure has served the research community exceptionally well throughout these decades. But perhaps this structure, now approaching 70 years old, can no longer accommodate the needs of the scientific community to thrive with uncertain funding dollars in our future. Admittedly, changing the structure of our most venerable and important funding entity is a daunting and scary prospect, and of course must be done with careful planning and implementation, and only after dutiful consideration of input from the scientific community-those most affected by a restructuring. One model for restructuring might engage the scientific community to identify and prioritize the most critical health challenges currently facing the U.S. population and constructing a funding portfolio that balances basic and clinical research to achieve goals agreed upon by the scientific community. This model would encompass the greater proportion of individuals in the U.S. suffering from acute or chronic disease and provide accountability for public awareness that these diseases are being properly addressed. This would also ensure that research dollars, i.e. tax dollars, are being targeted toward the most debilitating and costly health challenges faced by today's U.S. population. With a limited budget, this would entail bolstering funding for more common, serious diseases, while reducing funding for rarer diseases. Funding for rare diseases could be supplemented by disease-specific non-profit agencies. Difficulty choices would have to be made, but perhaps this might be a more productive and sensible approach for maintaining U.S. preeminence in research, rather than the traditional across-theboard cuts that usually result from budget shortfalls.

A re-prioritization of research funding might also benefit from a restructuring of the scientific review process. Current applications are assigned to Study Sections that limit critiques to general statements on significance, innovation, and approach penned by Reviewers who are often less acquainted with unique subject-specific concerns and limitations. In fact, most comments constructed by Reviewers simply rationalize the criterion score and do not provide sufficient detail for the applicant to learn and improve their research question or scientific approach. By contrast, a revised review process would draw upon established subject experts in the field to serve as Reviewers who could provide in-depth, subject-specific, constructive critiques that not only determine scientific merit, but also provide mentorship for bettering the scientific outcomes. This model would also provide opportunities for fellow scientists to develop a life-long cadre of collaborators and mentors; similar to the comraderies shared when the first Study Sections were assembled many years ago. Rather than serving as anonymous reviewers hidden behind the veil of Study Section panels, reviewers and applicants can collaborate freely through open critiques and suggestions with the goal of improving the application's funding status, and most important, improve the science. An open, team-based approach to reviewing applications by researchers with overlapping or closely associated interests might just provide the collective knowledge needed to foster innovative directions that benefit both Reviewers and Applicant. By this process, reviewing each other's research will then become less of a competition for few dollars and more about providing mutual mentorship by exchanging evidence-based argument that support or refute a creative hypothesis that challenges current paradigms and potentially opens new frontiers.

\section{A Final Note}

As a scientific community we cannot afford to wait for our funding woes to change. Our career life-times are limited and likely shorter than waiting out the current funding crisis. We must not only voice our demands for action to address our declining national scientific productivity, but we must also continue to offer examples for change that allow us to adapt and succeed even when facing an uncertain future. As part of our scientific training, we have all learned from our predecessors that some of the most unlikely and improbable discoveries laid the groundwork for remarkable change in our thought and in our approaches for improving human health. Likewise, even the most implausible idea for reforming our scientific review and funding process may cultivate extraordinary changes to restore our biomedical research capacity and provide stability for our future scientists.

\section{References}

1. Lee C, Sugimoto C, Zhang G, Cronin B (2013) Bias in Peer Review. JOURNAL OF THE AMERICAN SOCIETY FOR INFORMATION SCIENCE AND TECHNOLOGY 64: 2-17.

2. Smith R (2006) Peer review: A flawed process at the heart of science and journals. J R Soc Med 99: 178-182.

3. Day TE (2015) The big consequences of small biases: A simulation of peer review. Research Policy 44: 1266-1270.

4. Marsh HW, Jayasinghe UW, Bond NW (2008) Improving the peer-review process for grant applications: Reliability, validity, bias, and generalizability Am Psychol 63: 160-168.

5. Sattler DN, McKnight PE, Naney L, Mathis R (2015) Grant Peer Review: Improving Inter-Rater Reliability with Training. PLoS One 10: e0130450.

6. Moses H, lii, Matheson DM, Cairns-Smith S, George BP, et al. (2015) The anatomy of medical research: Us and international comparisons. JAMA 313 174-189.

7. McCarthy N (2015) The War On Terror Has Cost Taxpayers $\$ 1.7$ Trillion. Forbes Forbes, Jersey City, NJ. http://www.forbes.com/sites/niallmccarthy/2015/02/03/ the-war-on-terror-has-cost-taxpayers-1-7-trillion-infographic/

8. Geyman JP (2015) A five-year assessment of the affordable care act: Marke forces still trump the common good in u.s. Health care. Int J Health Serv 45: 209-225.

9. Stein S (2015) Congrats Young Scientists, You Face The Worst Research Funding In 50 Years. The Huffington Post. http://www.huffingtonpost com/2015/03/03/francis-colliins-nih-funding n 6795900.html

10. N. S. Foundation (2008) Research and Development: Essential Foundation for U.S. Competitiveness in a Global Economy. Arlington, VA. NSB 08-03

11. Rae-Dupree J (2013) US Scientists Are Leaving The Country And Taking The Innovation Economy With Them. Forbes Forbes, Jersey City, Jersey. http:// www.forbes.com/sites/janetraedupree/2013/09/25/us-scientists-are-leavingthe-country-and-taking-the-innovation-economy-with-them/ 
Citation: Orlando RA (2015) Our Current NIH Funding Dilemma: Reform Our Process Or Remain In The Bog? J Biomol Res Ther 4: 129. doi:10.4172/2167-7956.1000129

Page 3 of 3

12. Kristiansen C (2014) America is losing biomedical research leadership to Asia. Global Health Matters 13: 3-4.

13. Hand E, Mole B, Morello L, Tollefson J, Wadman M, et al. (2013) A back seat for basic science. Nature 496: 277-279.
14. Fang FC, Casadevall A (2010) Lost in translation--basic science in the era of translational research. Infect Immun 78: 563-566.

15. Grimes DA, Schulz KF (2002) Descriptive studies: what they can and cannot do. Lancet 359: 145-149. 